\title{
Additive manufacturing of concrete wall structures
}

\author{
Ekaterina Karpova ${ }^{1, *}$, Gintautas Skripkiunas ${ }^{1}$, Anastasiia Sedova $^{2}$, and Yelyzaveta \\ Tsimbalyuk $^{3}$ \\ ${ }^{1}$ Vilnius Gediminas Technical University, LT-10223, Vilnius, Lithuania \\ ${ }^{2}$ Kalashnikov Izhevsk State Technical University, 426069, Izhevsk, Russia \\ ${ }^{3}$ MC-Bauchemie, LT-51129, Kaunas, Lithuania
}

\begin{abstract}
D concrete printing is a perspective technology for sustainable construction and realization of sophisticated architectural projects. The current research proposes the thermal engineering calculation of wall structure based on the 3D printed concrete element of a total thickness of $150 \mathrm{~mm}$ with the internal air layer about $75 \mathrm{~mm}$. The 3D printing mixture was designed with the addition of perlite as filler in the dosage of $8 \%$ by weight of cement. The printing process was performed by the $3 \mathrm{D}$ printer of Contour Crafting type through the nozzle with a size of $20 \mathrm{~mm}$. The thermal engineering calculation was implemented for the A++ energy consumption class. The wall structure based on the $3 \mathrm{D}$ printed concrete element with perlit has the thermal resistance comparable with one for wall structures based on brick and aerated concrete. The total thickness of the designed wall structure with 3D printed concrete element decreased by 100 $\mathrm{mm}$ and $50 \mathrm{~mm}$ in comparison with wall structures based on brick and aerated concrete, respectively. In addition to the thermal engineering calculations, the visual assessment of the surface quality of 3D printed concrete wall elements was performed.
\end{abstract}

\section{Introduction}

Referring to CHCfE report, sustainable development consists of four pillars: cultural, social, economic, and environmental [1]. Based on this concept, additive manufacturing for wall structures is considered as an important component for future sustainable construction [2].

Undoubtedly, 3D printing of wall structures provides construction sectors with many impacts $[2,3]$. The majority of said impacts contribute to the sustainable development goals, listed in the 2030 Agenda for Sustainable Development by the United Nations Educational, Scientific and Cultural Organization (UNESCO) in 2015. Some of the goals, for instance № 9 "Industry, innovation and infrastructure" and № 11 "Sustainable cities and communities", have a direct connection with the use of additive technologies. At the same time, other goals can be filled by the use of such technologies, even if the connection is not obvious first. For example, 3D printing allows saving construction time [2], this also

\footnotetext{
*Corresponding author: ekaterina.karpova@vilniustech.lt
} 
contributes to the sustainable development goal №8 "Decent work and economic growth". Many scientists stress that additive manufacturing reduces the overall energy consumption and volume of wastes [4,5], this therefore fills sustainable goals № 3, 6, 13, 14, 15 by avoiding the use of formwork. Also, 3D printing impacts in the decrease of working hours required for the construction of particular buildings [2]. The said sustainable goals, to which the $3 \mathrm{D}$ printing can contribute, aim to transform our planet to a better place to live [6].

UNESCO stress the need in introducing and promoting new technologies [6], as such additive manufacturing introduces to produce surfaces of brand new architectural and aesthetic characteristics. Moreover, additive manufacturing enables the expansion of the variety of realized architectural forms.

Despite the significant advantages of additive manufacturing such as reduction of waste materials, saving time and labour, the wide application of the technology is limited. The anisotropy character of 3D printed concrete, absence of standard methods on its testing and corresponding normative documents inhibit the application of 3D printing technology in mass construction. The development of additive manufacturing and adoption of this technology to construction assumes the interdisciplinary approach in terms of material science, structural engineering, architecture, robotics and computation. One of the crucial aspects of $3 \mathrm{D}$ printing technology is a mix design of printing concrete mixture. The composition of the printing concrete mixture determines not only the properties of the material in the fresh state (rheology, pumpability, buildability), but also mechanical properties, structural performance and durability of the material in the hardened state. The application of supplementary cementitious materials, mineral additives and different types of chemical admixtures allow regulating the 3D printing concrete in the fresh and hardened state [7].

The aim of the present research is to evaluate the thermal properties and surface quality of $3 \mathrm{D}$ printed concrete wall elements prepared based on the mixture which involves perlite as a filler material.

\section{Materials and Methods}

Portland cement CEM I 42.5 R according to EN 197-1 was taken to produce the printing mixture. The chemical and mineral composition of cement is listed in Table 1. Applied cement has a specific gravity of $3.2 \mathrm{~g} / \mathrm{cm}^{3}$, a specific surface of $3.7 \mathrm{~cm}^{2} / \mathrm{g}$, initial and final setting time of $140 \mathrm{~min}$ and $190 \mathrm{~min}$, respectively. 2-day and 28-day compressive strength of used cement were equal to 28.9 MPa and 54.6 MPa, respectively.

Sand with fineness modulus of 2.6 was used as a fine aggregate in compliance with EN 12620. The sieve analysis results of applied sand are presented in Fig. 1.

Perlite with particle size distribution presented in Fig. 1 and specific gravity of about $1.1 \mathrm{~g} / \mathrm{cm}^{3}$ was taken as filler in concrete composition. Perlite is a siliceous volcanic glass with low density and high specific surface area. These features of perlite improve its ability to hold water and air pockets. Mainly, perlite consists of $\mathrm{SiO}_{2}$ and $\mathrm{Al}_{2} \mathrm{O}_{3}$ in the amount of about $73 \%$ and $16 \%$, respectively. The addition of perlite contributes to the formation of thick layers of mortar without sagging, improves thermal insulation and fire resistance properties [8-10].

Superplasticizer MC-Power Flow 586 with a dry content of about 30\% was chosen to achieve suitable flowability for the mixture.

Sodium silicate $\mathrm{Na}_{2} \mathrm{SiO}_{3}$ and accelerating admixture based on $\mathrm{Ca}\left(\mathrm{NO}_{3}\right)_{2}$ with a dry content of about $50 \%$ was added to accelerate the setting and increase the strength of the printing mixture. Applied chemical admixtures were complied with the requirements of EN 480. Mixing water meets the requirements of EN 1008. 
Table 1. Mineral and chemical composition of Portland cement

\begin{tabular}{|c|c|c|c|c|c|c|c|c|c|c|}
\hline $\begin{array}{c}\text { Chemi- } \\
\text { cal } \\
\text { compo- } \\
\text { sition, } \\
\text { (wt. \%) }\end{array}$ & 4.0 & 3.6 & 20.4 & 63.2 & 2.4 & 3.1 & 0.9 & 0.2 & 0.05 & $\begin{array}{c}2.1 \\
5\end{array}$ \\
\cline { 2 - 9 } & $\mathrm{Al}_{2} \mathrm{O}_{3}$ & $\mathrm{Fe}_{2} \mathrm{O}_{3}$ & $\mathrm{SiO}_{2}$ & $\mathrm{CaO}$ & $\mathrm{MgO}$ & $\mathrm{SO}_{3}$ & $\mathrm{~K}_{2} \mathrm{O}$ & $\mathrm{Na}_{2} \mathrm{O}$ & $\mathrm{Cl}^{-}$ & $\begin{array}{c}\mathrm{L} . \\
\text { O.I. }\end{array}$ \\
\hline $\begin{array}{c}\text { Mineral } \\
\text { compo- } \\
\text { sition, } \\
\text { (wt. \%) }\end{array}$ & \multicolumn{2}{|c|}{$\mathrm{C}_{3} \mathrm{~S}$} & $\mathrm{C}_{2} \mathrm{~S}$ & \multicolumn{2}{|c|}{$\mathrm{C}_{3} \mathrm{~A}$} & \multicolumn{2}{|c|}{$\mathrm{C}_{4} \mathrm{AF}$} & $\begin{array}{c}\text { Other } \\
\text { substances }\end{array}$ \\
\cline { 2 - 10 } & 56.6 & 16.7 & \multicolumn{2}{|c|}{9.0} & \multicolumn{2}{|c|}{10.6} & \multicolumn{2}{|c|}{7.1} \\
\hline
\end{tabular}

The dry components of the printing mixture were mixed in the process of dosing for about 6 min. Then, tap water with chemical admixtures was added, and mixing was continued for about 3-5 min.

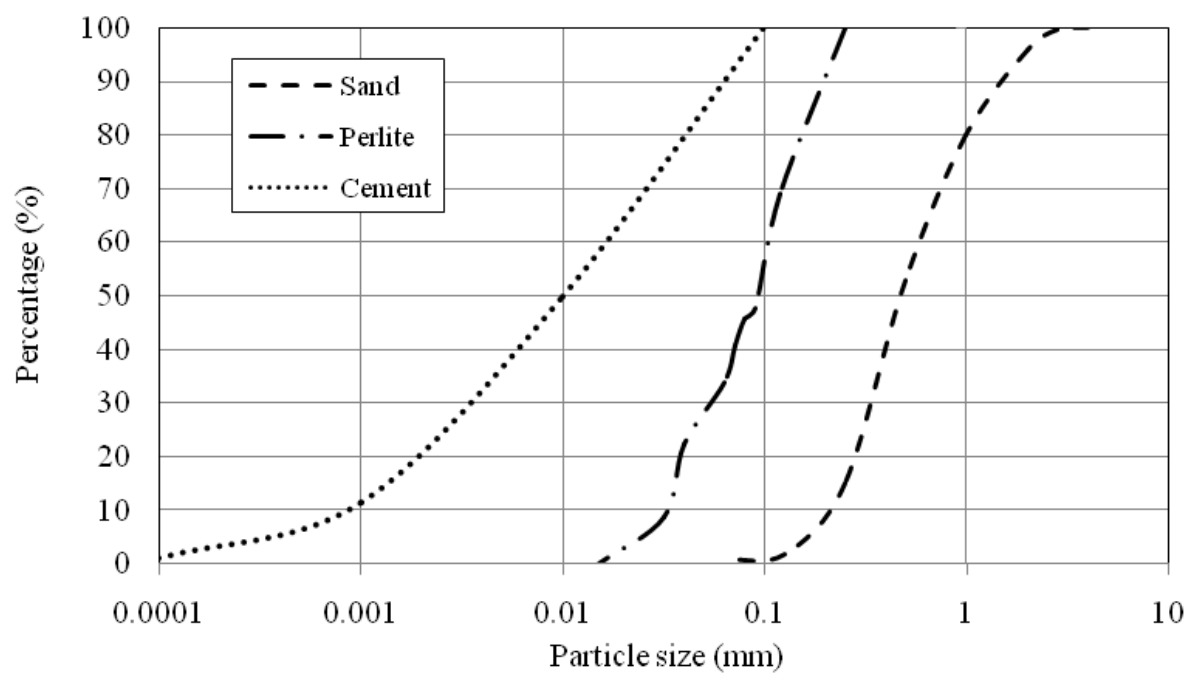

Fig. 1. Particle size distribution analysis of dry components

The mixture composition of the studied printing mixtures is presented in Table 2.

Table 2. Mixture proportion of printing mixture (\% by total mass).

\begin{tabular}{|c|c|c|c|c|c|c|c|}
\hline Component & Cement & Perlite & Sand & Water & Superplasticizer & $\begin{array}{c}\text { Accelerating } \\
\text { admixture }\end{array}$ & $\begin{array}{c}\text { Sodium } \\
\text { silicate }\end{array}$ \\
\hline Amount, \% & 36.8 & 3.0 & 44.9 & 14.1 & 0.8 & 0.4 & 0.1 \\
\hline
\end{tabular}

The layers of the printing mixture were extruded using a 3D printer of Contour Crafting type through the nozzle with a size of $20 \mathrm{~mm}$ (Fig. 2). 


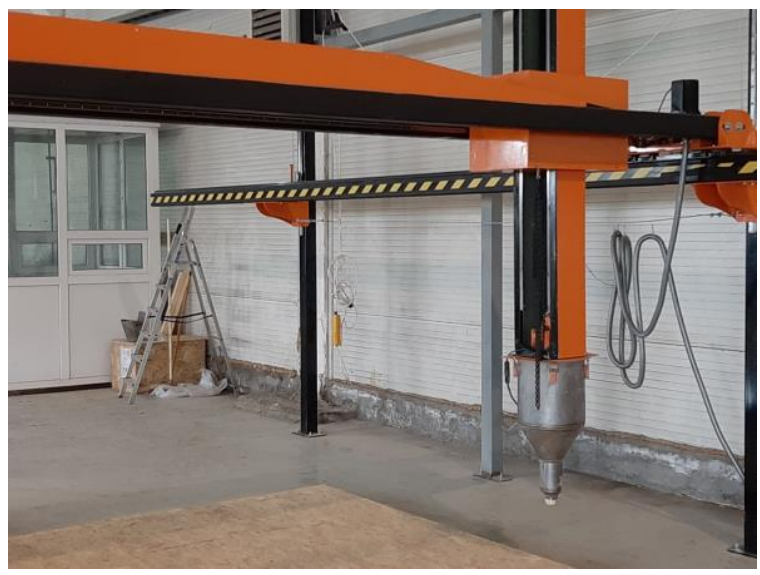

Fig. 2. Applied equipment for 3D printing

In the course of the research, samples with a size of 100x100x100 mm were extruded for testing of density and compressive strength. After extruding samples were compacted by shaking 5 times. The assessment of density and compressive strength were carried out according to EN 12350.

Based on the mentioned above concrete composition, the wall elements of size 1500x150x300 (h) mm were printed.

Thermal engineering calculation was performed based on the European requirements for the A++ energy consumption class. The surface quality of printed walls was visually assessed.

\section{Results and discussions}

\subsection{Thermal engineering calculation of printed wall structure}

The 3D printed concrete prepared according to the mix composition presented in Table 2 had a density of about $2100 \mathrm{~kg} / \mathrm{m}^{3}$ whereas compressive strength achieved the value of $71 \mathrm{MPa}$. The application of perlite in printing mixture contributes to the decrease in density of concrete without reduction in compressive strength. It can be a perspective way to make the concrete elements lighter, increase their thermal properties without loss of mechanical strength. Based on the known density of tested samples, it is possible to calculate the thermal conductivity coefficient according to V.P. Nekrasov's empirical formula [11]:

$$
\lambda=1.16 \sqrt{0.0196+0.22 \rho^{2}}-0.16
$$

where $\lambda$ is the thermal conductivity coefficient, $\mathrm{W} /(\mathrm{m} \cdot \mathrm{K}) ; \rho$ is the density of the material, $\mathrm{g} / \mathrm{cm}^{3}$.

The thermal conductivity coefficient $\lambda$ for studied $3 \mathrm{D}$ printed concrete was $0.99 \mathrm{~W} /\left(\mathrm{m} \cdot{ }^{\circ} \mathrm{C}\right)$. Based on the normative data of standards, it can be noticed that the thermal conductivity coefficient of printed concrete with perlite decreased by $\sim 34 \%$ in comparison with conventional concrete.

The printed element manufactured with this type of concrete composition is shown in Fig. 3. 


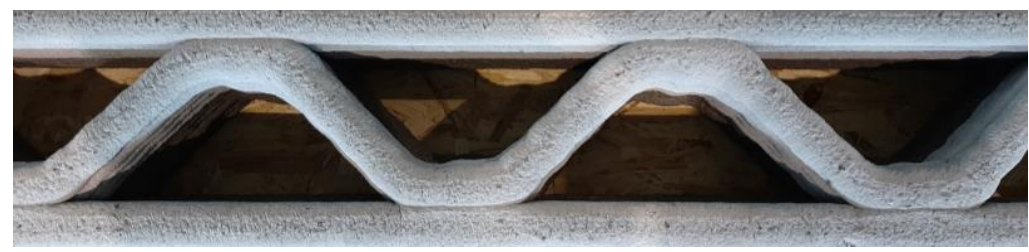

Fig. 3. 3D printed concrete element for wall structures.

Today, recent normative documents declared high requirements in terms of energy efficiency for newly constructed buildings. Most of new buildings have to be nearly zeroenergy consumption. European standards determined the class of buildings with almost zero-energy consumption as $\mathrm{A}^{++}$class. To reach this energy class, the development of new materials and structural decisions are necessary [12].

Let us accept the normative thermal resistance of external wall as $R_{N} \sim 9.62 \mathrm{~m}^{2} \cdot \mathrm{K} / \mathrm{W}$. Total thermal resistance of external wall structure $R t$ can be determined based on the standard Equation [12]:

$$
R_{t}=\frac{1}{R_{s i}}+\frac{1}{R_{s l}}+\frac{1}{R_{s e}}
$$

where $R_{t}$ is the total thermal resistance of the external wall, $\mathrm{m}^{2} \cdot \mathrm{K} / \mathrm{W} ; R_{s i}$ is the thermal resistance of the internal surface of the wall, $\mathrm{m}^{2} \cdot \mathrm{K} / \mathrm{W} ; R_{s l}$ is the sum of the thermal resistance of wall layers, $\mathrm{m}^{2} \cdot \mathrm{K} / \mathrm{W} ; R_{s e}$ is the thermal resistance of the external surface of the wall, $\mathrm{m}^{2} \cdot \mathrm{K} / \mathrm{W}$.

In order to fulfil the requirements of the European standards for $\mathrm{A}^{++}$class, printed wall structure has to be supplemented by insulation material (for instance, polystyrene foam mats with $\lambda \sim 0.029 \mathrm{~W} /(\mathrm{m} \cdot \mathrm{K}))$. The scheme of possible structure with the $3 \mathrm{D}$ printed wall element for preliminary evaluation of thermal properties is shown in Fig. 4a. With the covering of the printed wall by insulation material and plaster layer, the total thermal resistance of external wall $R_{t}$ will be about $10.02 \mathrm{~m}^{2} \cdot \mathrm{K} / \mathrm{W} \geq R_{N}=9.62 \mathrm{~m}^{2} \cdot \mathrm{K} / \mathrm{W}$.

The total thermal resistance of external $3 \mathrm{D}$ printed wall was compared with constructions with ordinary clay brick $(\lambda \sim 0.56 \mathrm{~W} /(\mathrm{m} \cdot \mathrm{K}))$ and aerated concrete $(\lambda \sim 0.29 \mathrm{~W} /(\mathrm{m} \cdot \mathrm{K}))($ Fig $4 \mathrm{~b}, \mathrm{c})$. The equal thickness of insulation material and plaster layer was taken for the wall structure. The comparison was performed by the total thickness of walls and their total thermal resistance. According to calculation, the total thermal resistance of brick wall with insulation material and plaster layer was $9.96 \mathrm{~m}^{2} \cdot \mathrm{K} / \mathrm{W}$ $\left(\geq R_{N}=9.62 \mathrm{~m}^{2} \cdot \mathrm{K} / \mathrm{W}\right)$. The total thickness of the wall structure with brick was equal to $540 \mathrm{~mm}$. As for the wall structure with aerated concrete, the total thermal resistance and total thickness were $10.20 \mathrm{~m}^{2} \cdot \mathrm{K} / \mathrm{W}\left(\geq \mathrm{R}_{\mathrm{N}}=9.62 \mathrm{~m}^{2} \cdot \mathrm{K} / \mathrm{W}\right)$ and $490 \mathrm{~mm}$, respectively. 


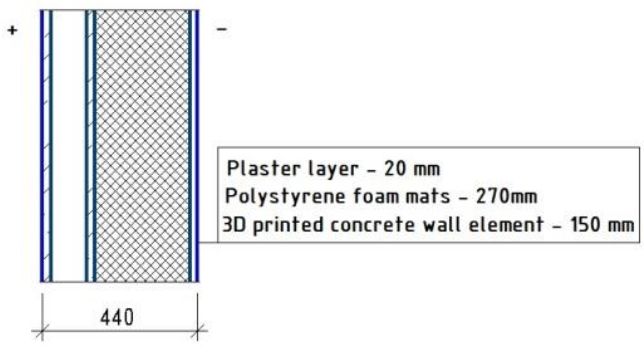

a)

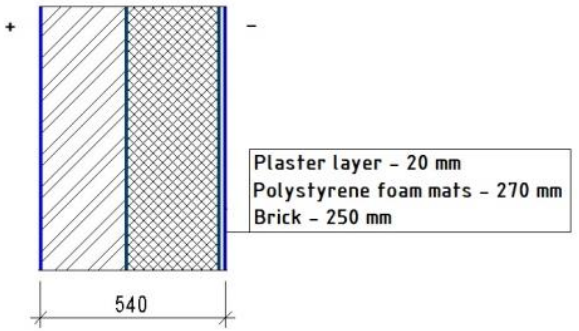

b)

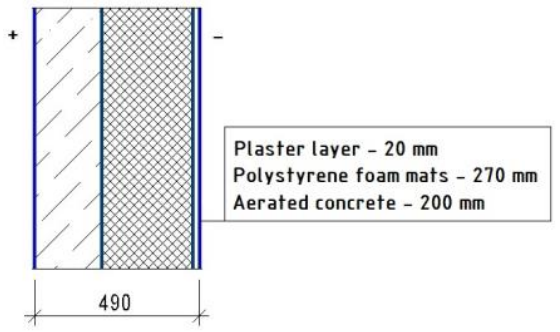

c)

Fig. 4. Scheme of wall structures for thermal engineering calculation with: a) 3D printed concrete wall elements; b) brick; c) aerated concrete

The results of calculation for all considered wall structures are shown in Fig. 5.

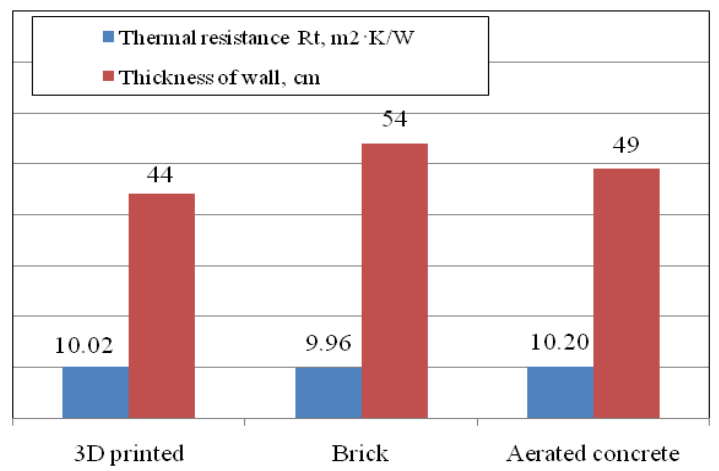

Fig. 5. Thermal resistance and total wall thickness of studied wall structures

Thermal engineering calculation results (Fig. 5) demonstrate that 3D printed wall structure has parameters comparable with parameters for traditional materials used in construction practice. Moreover, the usage of 3D printed wall elements enables to decrease of the total thickness of the designed wall. In comparison with brick and aerated concrete wall, the total wall thickness was decreased by $100 \mathrm{~mm}$ and $50 \mathrm{~mm}$, respectively.

\subsection{Surface quality}

First, printed surfaces consist of filaments, thanks to the printing technology; this can be used for the creation of surface patterns. Forms of filaments depend on the nozzle geometry and layer height $[5,13]$. The surfaces obtained in the course of the research are shown in Fig. 6. Smooth-shaped filaments are the most well-known (see Fig. 6a, b). Standard looking 
surface made of such filaments can be made different by changing an extruder tool path at each layer, thanks to the special printing software (see Fig. 6c). This method gives an opportunity to have a finish facade surface of high architectural quality, with no need for facade panels.

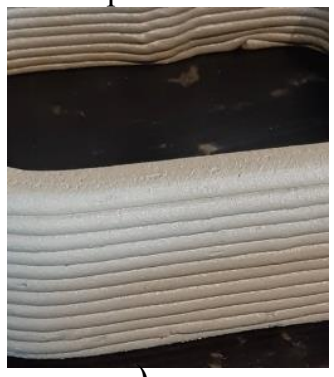

a)

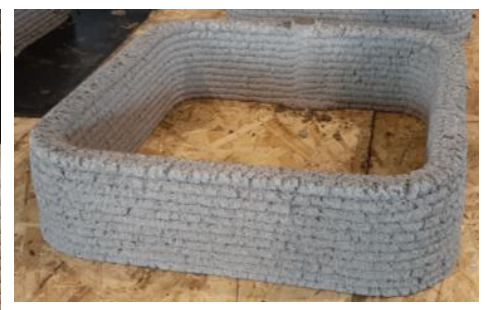

b)

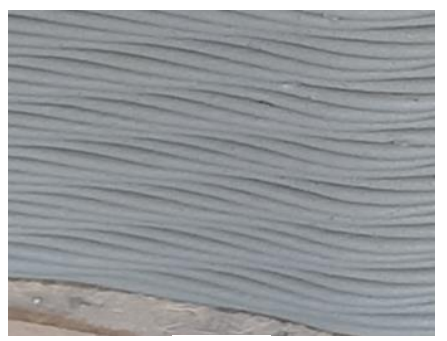

c)

Fig. 6. 3D printed surface: a) with smooth-shaped filaments; b) with smooth-shaped filaments and defects; c) relief surface gained by the extruding filaments based on the changed tool path

Since printed structures may be left without additional decorative covering, more attention should be paid to the characteristics of the printing mixture. One of the crucial aspects of 3D printing mix design is the content of water and suitable consistency. When the content of water is not enough and the concrete mixture has a quite rigid consistency, the surface of the 3D printed structure can have defects of filaments as it is presented in Fig. 6b.

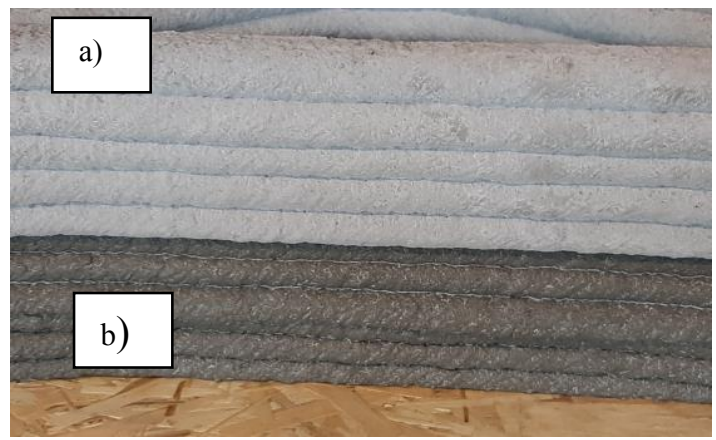

Fig. 7. 3D printed surface with various mix composition: a) with perlite; b) without perlite

The composition of the printing mixture is one of the most important aspects which influence the aesthetic characteristics of printed buildings. Various additives and admixtures can influence the colours of the printing mixture. For instance, the addition of perlite in current research brightens the surface colour in comparison with the surface without perlite modification (Fig. 7).

Along with the concrete printing composition and applied tool path of printing, the surface quality of concrete wall structures depends on the curing process. Fig. 8 shows the surface quality of $3 \mathrm{D}$ printed wall structures which were covered by the polyethylene film and without it. 


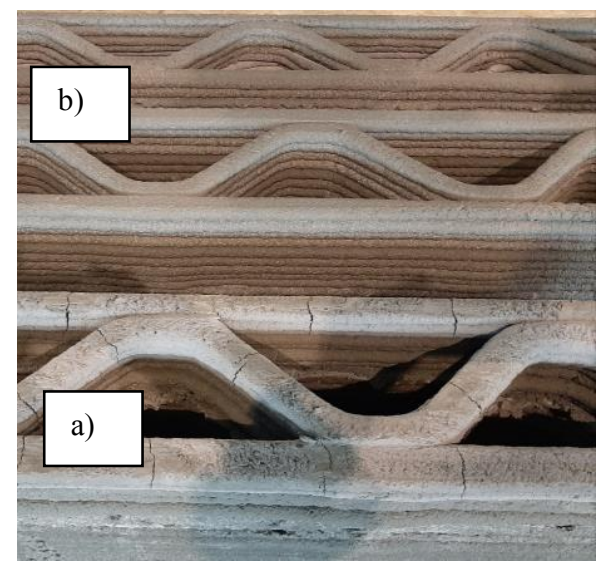

Fig. 8. 3D printed surface: a) without covering by the polyethylene film; b) with covering

The 3D printed concrete wall structure presented in Fig. 8a has the number of cracks which can be linked with the absence of a suitable curing process and fast evaporation of water which cause cracking processes. Opposite to the wall structure in Fig. 8a, the wall structure in Fig. $8 \mathrm{~b}$ does not have any cracks which can be explained by the sufficient curing of the structure.

\section{Conclusion}

Additive manufacturing or 3D printing technology is a perspective way to produce sustainable structures with various sophisticated architectural design automatically. This technology should be considered in terms of material science, architecture, structural design, robotics etc.

In the course of the present research, the thermal properties and surface quality of 3D printed concrete wall elements prepared based on the mixture with perlite as a filler material were evaluated.

The thermal engineering calculation for A++ energy consumption class showed that the wall structure based on the 3D printed concrete element with perlite has the thermal resistance comparable with one for traditional construction materials as brick and aerated concrete. The total thickness of the designed wall structure with 3D printed concrete element decreased by $100 \mathrm{~mm}$ and $50 \mathrm{~mm}$ in comparison with brick and aerated concrete, respectively.

The research also demonstrates the importance of such aspects as type of tool path of extrusion, mix design and curing conditions in order to reach high quality surface of printed structures with required architectural design. The addition of perlite to the studied printing concrete mixture led to the surface lightening in comparison with composition without filler.

\section{References}

1. CHCfE Consortium Cultural Heritage Counts for Europe (2015)

2. I. Hager, A. Golonka, R. Putanowicz. Proc. Eng. 151, (2016)

3. M. Sakin, Y.C. Kiroglu, En. Proc. 134, (2017)

4. H. Yang, J.K.H. Chung, Y. Chen, Y. Li, J. Wirel. Commun. Netw. (2018) 
5. M.T. Souza, I.M. Ferreira, E.G. de Moraes, L. Senff, A.P.N. de Oliveira, J. Build. Eng. 32, (2020)

6. UNESCO Engineering for sustainable development: delivering on the Sustainable Development Goals (2021)

7. B. Lu et al. Constr. Build. Mater. 207, (2019)

8. J.P. Ingham, Geomaterials Under the Microscope (Academic Press, 2013)

9. J. Dehn, S. R. McNutt, The Encyclopedia of Volcanoes (Academic Press, 2015)

10. O. Sengul et al. Energ. Buildings 43, (2011)

11. V. G. Mikulsky et al., Building Materials (in Russian) (ACB, 2000)

12. D. Aviža, Z. Turskis, A. Święcicki. Technical transactions, Civil Engineering 4-B, (2015)

13. J. Zhang, et al. Composites Part A 125 (2019) 